\title{
ACÚMULO DE FERRO NO FÍGADO DE UM TUCANO (Ramphastos toco) - RELATO DE CASO
}

(Iron accumulation on a liver of a toucan (Ramphastos toco) - Case report)

${ }^{1}$ Maraya Lincoln Silva, ${ }^{2}$ Matheus Alves Moreira, ${ }^{2}$ Gustavo Bauer Costa da Silva, ${ }^{2}$ Adriano Bauer Costa da Silva

1 Universidade Estadual Paulista Júlio de Mesquita Filho (UNESP), Campus de Jaboticabal, São Paulo, Brasil. ${ }^{2}$ Clínica Veterinária Amazoo Pets de Jundiaí, São Paulo, Brasil.

*Correspondência: marayals@yahoo.com.br

RESUMO: O acúmulo de ferro ou hemocromatose é uma enfermidade caracterizada pelo acúmulo exacerbado de grânulos de hemossiderina nos tecidos de vários órgãos, afetando a morfologia e funcionamento destes devido a concentrações elevadas no organismo. Os principais órgãos acometidos são fígado, baço, medula óssea e reticulócitos. A hemossiderina é um derivado da hemoglobina formado por moléculas de ferritina, que são ricas em ferro (MASSAROTTO; GONÇALVES, 2010). A hemocromatose em aves não possui etiologia bem definida, estando relacionada ao excesso de ferro na dieta, falta de controle na absorção intestinal deste microelemento e predisposição genética. Os tucanos e araçaris (família Ramphastidae) com grande frequência são acometidos pela hemocromatose, sendo uma das doenças mais comuns nesta família. Os sinais clínicos costumam ser subclínicos, com frequente ocorrência de morte súbita. Outros sinais incluem apatia, anorexia, perda de peso, ascite, dispneia, hepatomegalia, cardiomegalia e debilidade progressiva (CUBAS, 2008). O presente estudo tem como objetivo relatar a ocorrência da doença do acúmulo de ferro em um tucano-toco, bem como as alterações e achados histopatológicos encontrados nesta frequente alteração. Foi recebido para atendimento na Clínica Veterinária Amazoo Pets, localizada no município de Jundiaí, São Paulo um exemplar de tucano-toco (Ramphastos toco). No exame clínico o animal apresentava dispneia, apatia, fraqueza e dificuldade de manter-se em estação. Este veio a óbito no mesmo dia, e foi encaminhado para o Setor de Patologia da mesma clínica veterinária. Durante a realização do exame necroscópico foi observado hepatomegalia acentuada, órgão com coloração acastanhada, bordos regulares e consistência normal. Foram colhidos fragmentos do fígado e fixados em solução de formalina a $10 \%$, para posterior processamento histológico e avaliação microscópica. As lâminas foram coradas com o corante de Hematoxilina e Eosina (HE) e Reação Azul da Prússia (Técnica de Pearls). Na coloração HE foi possível observar: Discreta degeneração gordurosa, caracterizada pelo acúmulo de glóbulos de gordura no citoplasma dos hepatócitos, deslocando assim, o núcleo para a periferia celular. Acentuadas áreas de acúmulo de pigmento derivado a hemoglobina: hemossiderina, encontrada no interior de macrófagos teciduais e espaços intercelulares. Através da coloração Azul da Prússia, foi também possível evidenciar o acúmulo de hemossiderina em tecido hepático. Somando os achados clínicos, macroscópicos e confirmação microscópica, foi possível diagnosticar a doença do acúmulo de ferro em um tucano.

Palavras-chave: hemocromatose; histopatologia; Ramphastidae.

\section{Referências}

CUBAS, Z. S. Siderose Hepática em Tucanos e Araçaris. Dissertação. Universidade Federal do Paraná - UFPR, Curitiba, 158p., 2008.

MASSAROTTO, V. M.; GONÇALVES, G. A. M. Hemocromatose em Aves da Família Ramphastidae. Veterinária e Zootecnia. Vol. 17, N4, p. 450-460, 2010. 